\title{
Camel collision as a major cause of low cervical spinal cord injury
}

\author{
Sohail Ansari and KSM Ashraf Ali \\ Department of Neurosciences and Rehabilitation Medicine, Riyadh Armed Forces Hospital, Riyadh, Saudi Arabia
}

\begin{abstract}
One hundred and forty patients with low cervical spinal cord injuries, who were admitted to the Riyadh Armed Forces Hospital over the past 10 years were reviewed. Motor vehicle accidents constituted $119(85 \%)$ of the patients. Camel collisions were a major cause of vehicle accidents $39(33 \%)$, after rollover accidents $70(59 \%)$, and much more than head on collisions $9(7.5 \%)$. Male to female ratio was $14: 1$ with a mean age of 32 years. Camel collision although a commonly observed cause of motor vehicle accidents in the Middle East has not been mentioned in the literature before. The mechanism of injury is not much different, but the exact description of the accident and sustaining injury is interesting because it leads to localised damage to the neck without major body trauma and mortality.
\end{abstract}

Keywords: camel collision injuries; spinal cord injury; prevention

\section{Introduction}

Low cervical spine injuries constitute up to $53 \%$ of the spinal cord injuries ${ }^{1}$ and are the most common reasons for admission into a spinal injuries unit. The different causes of cord injury vary with sex, race and age ${ }^{1}$ being influenced by activities and hazards prevalent in each population. $^{2}$ (Table 1).

We have reviewed 119 low $(\mathrm{C} 5-\mathrm{C} 7)$ cervical spine injuries admitted to the Riyadh Armed Forces Hospital (RAFH) rehabilitation unit after road accidents over the past 10 years (Table 2). We compared the various causes with those from Western Europe and North America (Table 1). Thirty-nine patients were involved in injuries resulting from direct collision with camels which has not been previously reported.

\section{Methods}

We looked at the 119 patients with quadriplegia resulting from road traffic accidents, which constituted $85 \%$ of our patients with low cervical spine injuries (140 patients). Retrospective analysis was performed from our multi disciplinary case records and radiological workup on these patients. Since regular follow up was maintained queries arising during our study were resolved during their outpatient visits.

We looked at the age, gender, type or mechanism of injury, whether the person affected was a driver or passenger, the type of vehicle involved, level and completeness of injury to the spinal cord, associated

Correspondence: Riyadh Armed Forces Hospital, W939, P.O. Box 7897, Riyadh 11159, Saudi Arabia injuries and mortality. Fourteen of the patients involved with the camel collision injuries were reinterviewed and further information was obtained from the patients or their partners present at the time of accident.

\section{Results}

The mean age of patients involved in road traffic accidents was 32 years, with a range from $16-80$ years. The male to female ratio was $14: 1$ (111:8). The distribution and the pattern of injuries, associated mortality, type of vehicle, passenger driver distribution and associated injuries are shown in Tables 3 and 4. Thirty-nine had collisions with camels.

None of the patients were pedestrians or were involved in a motor cycle or bicycle accident. The

Table 1 SCI comparison with two studies in UK and USA

\begin{tabular}{lccc}
\hline & $\begin{array}{c}\text { * } \begin{array}{c}\text { Birming- } \\
\text { ham }\end{array} \\
\text { AL USA }\end{array}$ & $\begin{array}{c}{ }^{\dagger} \text { Salisbury } \\
\text { UK }\end{array}$ & Riyadh SA \\
\hline Motor vehicle accidents & $47.7 \%$ & $36 \%$ & $79.2 \%$ \\
Falls or falling objects & $20.8 \%$ & $37 \%$ & $10.4 \%$ \\
Sports & $14.2 \%$ & $20.5 \%$ & $3 \%$ \\
$\begin{array}{c}\text { Rest (violence, gunshot, } \\
\quad \text { major disasters etc) }\end{array}$ & $14.6 \%$ & $6.5 \%$ & $7.4 \%$ \\
\hline
\end{tabular}

*Kennedy et al. (1986). Spinal Cord Injury: The facts and figures. Birmingham AL: The University of Alabama Spinal Cord Injury Statistical Centre. ${ }^{\dagger}$ Grundy D. Swain A. At the Accident. In: $A B C$ of Spinal Cord Injury. 3rd ed. BMJ Publishing Group: London 1996, p1. 
most common mechanism was a flexion injury, followed by vertical compression, hyper-extension, lateral flexion and flexion rotational injuries. These mechanisms were ascertained by obtaining an accurate account of the events given by the patient or an accompanying person, rather than by relying on the radiological findings.

\section{Discussion}

Because of relatively poor mechanical stability the cervical spine is more vulnerable to trauma than are other areas of the vertebral spine. ${ }^{3}$ Moreover injury to the spine in this region is likely to result in damage to the cord in $40 \%$ of cases. ${ }^{4}$ As a result a disproportionate number (approximately 53\%) of spinal cord injuries occur in cervical spine. ${ }^{1}$

Road traffic accidents account for $85 \%$ of low cervical spine injuries in our study. Comparison of the spinal injury pattern can be compared in the three units in UK, USA and Saudi Arabia in Table 1

The radiographic appearances of the spine after injury are not a reliable guide to the severity and exact mechanism of injury, and only represent the final or recoiled position of the vertebrae and do not

Table 2 Distribution of low cervical injuries at RAFH

\begin{tabular}{lcrl}
\hline Level & Complete injuries & Incomplete injuries & Total \\
\hline C5 & $31.9 \%(38)$ & $16.8 \%(20)$ & $48 \%(58)$ \\
C6 & $20.1 \%(24)$ & $5.8 \%(7)$ & $26 \%(31)$ \\
C7 & $14.2 \%(17)$ & $4.2 \%(5)$ & $18.4 \%(22)$ \\
C8 & $5 \%(6)$ & $1.6 \%(2)$ & $6.7 \%(8)$ \\
Total & $71.2 \%(85)$ & $28.4 \%(34)$ & $100(119)$ \\
\hline
\end{tabular}

Table 3 Patient location in the vehicle

\begin{tabular}{lcll}
\hline $\begin{array}{l}\text { Vehicle } \\
\text { involved }\end{array}$ & $\begin{array}{c}\text { Number of } \\
\text { vehicles }\end{array}$ & \multicolumn{1}{c}{ Driver } & Passenger \\
\hline Saloon & $58 \%(69)$ & $59 \%(41)$ & $40.5 \%(28)$ \\
Jeep & $8.5 \%(10)$ & $80 \%(8)$ & $20 \%(2)$ \\
Pickup & $33.5 \%(40)$ & $62.5 \%(25)$ & $37.5 \%(15)$ \\
Total & & 74 & 45 \\
\hline
\end{tabular}

necessarily indicate the forces generated in the injury. $^{2}$ Therefore these mechanisms were based on the near accurate account of the accidents given by the patient or other passengers in the vehicle.

\section{Camel accidents}

In Saudi Arabia, the camel is the traditional animal of the desert. Motor vehicles are the most common mode of transport in Saudi Arabia because of large families, cheap petrol and comparatively good roads passing through extensive deserts. During the day time, a burst tyre produced by road heat is the common cause of single vehicle roll over accidents, followed by head on collision. This is because of a lack of divided highways, high speed, driver exhaustion and fatigue from uninterrupted long journeys.

Camel collisions are common in the evening time as camels who stay in the desert, mostly unsupervised, move around in herds of 4-6, often coming on to the roads without warning. There are no designated crossing points for the camels and the fencing erected in various places is often disrupted by camel owners to enable the camels to cross over. They appear unexpected as a herd on the road (Figure 1). There is no space or chance for the driver to manoeuvre or swerve to avoid the collision. Pick up trucks are the

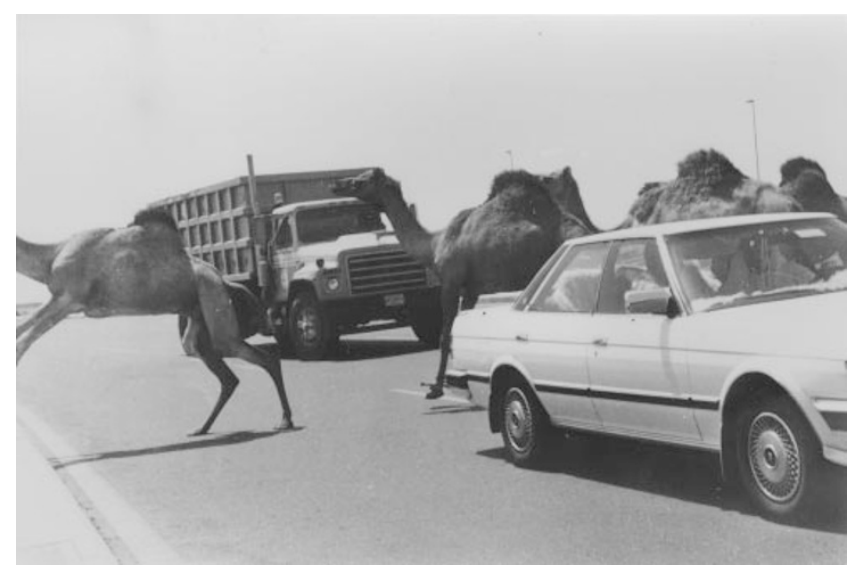

Figure 1 A herd of camels crossing the road seemingly oblivious to vehicles

Table 4 Pattern of low cervical spine injuries

\begin{tabular}{|c|c|c|c|c|c|}
\hline & & \multicolumn{4}{|c|}{$\begin{array}{l}\text { Associated injuries } \\
\text { Abdominal requiring }\end{array}$} \\
\hline & & Head $(G C S<11)$ & Chest ( Rib \# etc) & laparotomy & Multiple \\
\hline Roll over single vehicle & $59 \%(70)$ & $7 \%(5)$ & $10 \%(7)$ & $0.7 \%$ & $1.4 \%(10)$ \\
\hline Head on collision & $7.5 \%$ & $22 \%(2)$ & $22 \%(2)$ & $11 \%$ & $33 \%(3)$ \\
\hline Camel Accidents & $33 \%(39)$ & $25 \%(10)$ & $5 \%(2)$ & 0 & 0 \\
\hline $\begin{array}{l}\text { Other (pedestrians, } \\
\text { bicycle, motorcycle) }\end{array}$ & 0 & 0 & 0 & 0 & 0 \\
\hline
\end{tabular}

bicycle, motorcycle)

Male:Female 111:8 14:1 Age Range 16-80 Mean Age 32.78 
most commonly used vehicle in the desert and are often the vehicle involved in camel collisions.

\section{Mechanism of injury}

As the vehicle hits the feet of this tall animal, the camel's body lands on to the roof, above the front seat or crashes through the front of the windscreen hitting the front seat occupants (Figure 2). Persons usually involved assume a protective flexion posture to avoid the injury flexing their neck and if unrestrained bending forward. The impact is sustained by the occiput and the cervical spine dorsally. If the person is restrained, vertical compression to the neck results in compression fractures, or a direct strike to the face results in an extension injury. The other protective posture which the person adopts is side lying on the seat to avoid direct impact of the animal coming through the windscreen. This multitude of force factors acting on the spine, creates a fracture pattern resulting in flexion, extension, rotational or horizontal compression injury.

Of the 39 patients with camel collision injuries, $25 \%$ had associated head injuries with only $5 \%$ sustaining chest injuries. This may be due to the localised impact of the body of the camel to the head and neck and at times the chest if the impact is from the front.

Deaths from these accidents have been reported in newspapers, but none of our patients died. This may be due to the isolated injuries to the neck and occiput as compared to multiple injuries resulting from head on collision.

\section{Recommendations}

Although a number of recommendations have been made to improve the road transport system to avoid these camel collision injuries, including penalising the camel owners for leaving their animals unsupervised, erection of fencing, illumination of roads, speed restrictions and radar monitoring of the highways, the accidents continue to occur. More stringent regulations are required and better public awareness is required as well as the improved education of camel

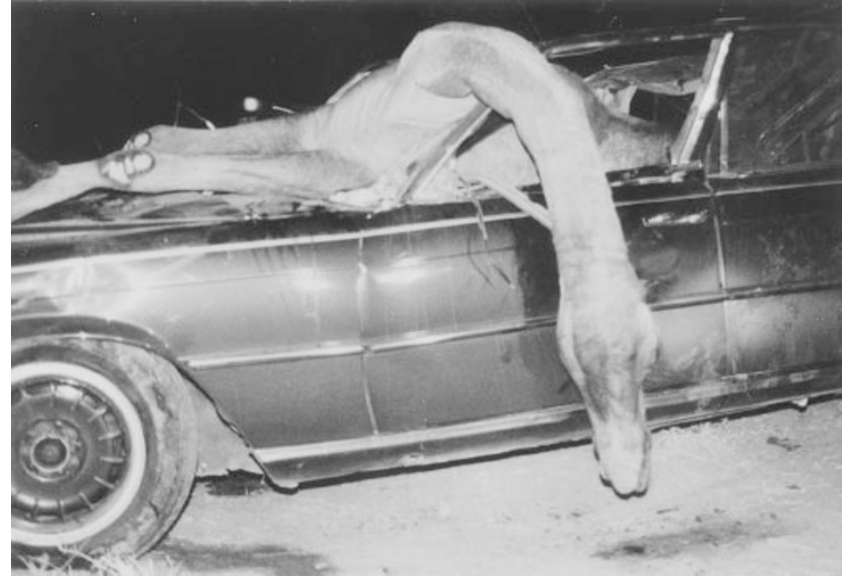

Figure 2 Camel crashing through the car roof and windscreen

owners. Accident prevention programmes should be started in schools and the media. Affected persons need to form spinal injuries associations to increase general awareness of the dangers.

\section{Acknowledgements}

We extend our sincere gratitude to $\mathrm{Mr}$ David Grundy for reviewing this article, Mrs M Alvares for her secretarial support, $\mathrm{Mr}$ Khalid Al Moosa and $\mathrm{Mr}$ Sulaiman Al Saikhan for photographs and suggestions.

\section{References}

1 Kennedy E, Stover S, Fine P. (eds). Spinal Cord Injury: The facts and figures. Birmingham, AL: The University of Alabama Spinal Cord Injury Statistical Center.

2 Grundy D, Swain A. At the Accident. In: ABC of Spinal Cord Injury, 3rd ed. BMJ Publishing Group: London 1996, p1.

3 Meyer P. Surgical stabilization of cervical Spine. Surgery of Spinal Trauma. Churchill Livingstone: New York. pp 315-316.

4 Cook P. Radiology of Spine and Spinal Cord Injury. In: L. Illis (Ed) Spinal Cord Dysfunction Assessment. New York: Oxford University Press. pp $41-103$. 